\title{
CHANGES IN THE TWINNING RATE IN CANADA 1926-70
}

\author{
J. MARK ELWOOD \\ Department of Epidemiology and Community Medicine, University of Ottawa, Canada
}

Large variations in the 'twinning rate', i.e., the ratio of twin confinements to total confinements, between different countries and between different time periods have been reported by many authors. Apart from well documented variations in twinning rate with maternal age and parity, little is known of the causes of these variations, which mainly affect dizygotic twinning.

James (1972) has reported rapid falls of $20-25 \%$ in dizygotic twinning rates in nine European countries, Australia, and New Zealand, starting abruptly between 1956 and 1964 . He does not assess the effect of age and parity changes but quotes a survey in Aberdeen (MacGillivray, 1970) which shows that there the fall affected both primigravidae and multigravidae at all ages. James suggests that food additives might be involved.

Jeanneret and MacMahon (1962) showed that the dizygotic rate in the United States of America fell irregularly from 1922 to 1958 , but this fall affected only mothers over the age of 30 . They also reported a dizygotic and monozygotic peak, in all age groups, in 1946. They were able to show that these changes were largely independent of maternal age and parity changes. The USA rate in 1964 showed a further fall (Allen and Schachter, 1970).
In view of the differences in these interpretations a study of Canadian rates from 1926 to 1970 is reported here.

\section{Method}

Annual summaries of livebirths and stillbirths of over 28 weeks' gestation were obtained from Statistics Canada (Vital Statistics, annual reports 1926-70); these give multiple births by maternal age, and total births by age and parity, for Canada, excluding Newfoundland. Before 1952, the data also exclude the Yukon and the North West Territories $(0.2 \%$ of the total population) and give only total multiple births, and total births by maternal age; no data by parity are available. However, for this earlier period, the sex-type of each twin pair is recorded, allowing calculation of monozygotic and dizygotic rates. Because of these differences i available data, the two time periods are treated somewhat differently.

\section{RESULTS}

Figure 1 shows the twinning rate, i.e., the number of pairs of twins per thousand total confinements, including both livebirths and stillbirths of over 28 weeks' gestation.

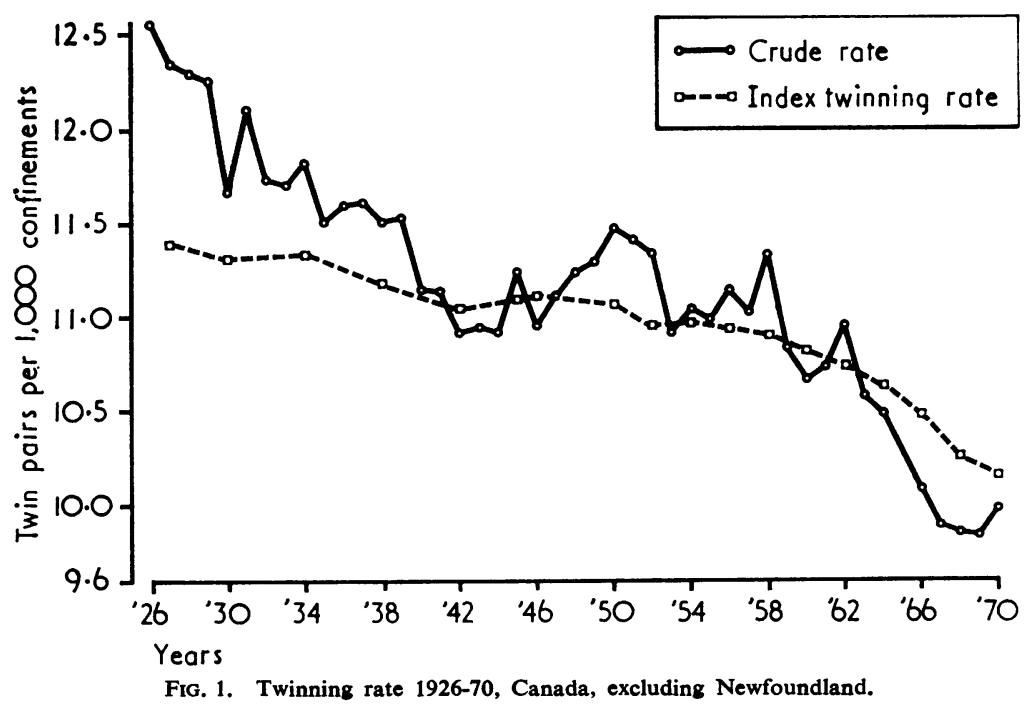


There has been a fall of $20 \%$ in the crude twinning rate between 1926 and 1970 . Within this period there is a fairly steady decline from 1926 to 1942 and again from 1958 to 1970; between 1942 and 1958 the rate could be interpreted as rising slowly or else being almost steady with an isolated rise in 1945 and a large rise centred on 1950. The general trend appears similar to that reported by Jeanneret and MacMahon (1962) for the USA.

\section{Effect of Maternal Age}

Previous studies, e.g., Waterhouse (1950) and Bulmer (1959a), have shown that the twinning rate rises with maternal age to a maximum between 35 and 40 , due almost entirely to a rise in dizygotic twinning. Thus, secular changes may be due to changes in the age structure of the maternal population.

To assess this effect, age specific twinning rates for five-year age groups were calculated for the 1952-56 pooled maternal population and applied to the maternal population for other years to give the index twinning rate, shown by the dotted line in Figure 1. This is the twinning rate expected if these age specific rates had applied; thus, the changes in the index twinning rate show changes expected solely due to changes in maternal age distribution, and the differences between it and the crude twinning rate indicate changes in twinning independent of maternal age. It is evident that a considerable amount of the decline in twinning rates is due to maternal age changes. This is also expressed in Table I, which compares the changes in observed rates between the five-year periods 1927-31, 1952-56, and 1966-70 with the changes in the index rates. Between 1927-31 and 1952-56 there was a fall of 1.036 per thousand in the twinning rates, whereas a fall of $0.225(21.7 \%$ of that observed) would be expected from changes in maternal age distribution. Between 1952-56 and 1966-70 the observed fall was $1 \cdot 171$, of which $0 \cdot 797$ $(68 \cdot 1 \%)$ is expected from age changes alone.

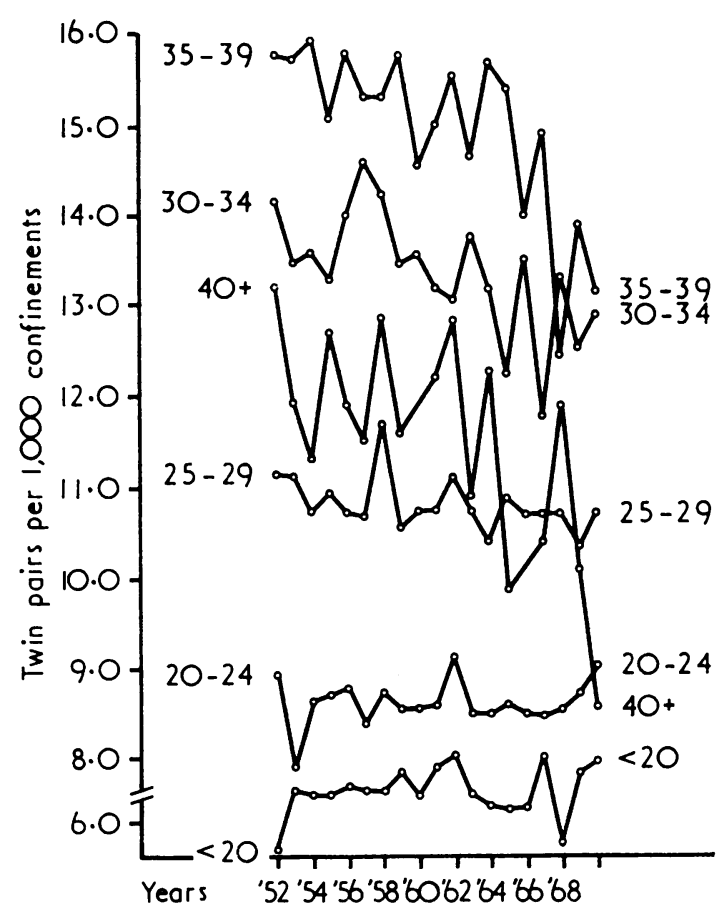

FIG. 2. Canadian age-specific twinning rates, 1952-70.

From 1952 onwards, age-specific twinning rates can be calculated and these are shown in Figure 2. It is clear that whereas a decline is seen in mothers over 30 , there is no consistent change in younger age groups.

\section{EFFECT OF PARITY}

Dizygotic twinning increases with parity independently of age (Bulmer, 1959a), and so a reduction in parity within each age group might account for the decrease in twinning rate still seen after correction for maternal age. Unfortunately, the parity of mothers of twins is not recorded so no

TABLE I

CHANGES IN CRUDE AND INDEX TWINNING RATES

\begin{tabular}{|c|c|c|c|c|c|c|c|}
\hline \multicolumn{3}{|c|}{ Period } & $\begin{array}{l}\text { Crude Twinning } \\
\text { Rate per 1,000 } \\
\text { Confinements }\end{array}$ & $\begin{array}{c}\text { A } \\
\text { Change from } \\
\text { Previous Period }\end{array}$ & $\begin{array}{c}\text { Index Twinning } \\
\text { Rate }\end{array}$ & $\begin{array}{c}\text { B } \\
\text { Change from } \\
\text { Previous Period }\end{array}$ & $\frac{B}{A} \times 100 \%$ \\
\hline $\begin{array}{r}1927-31 \\
1952-56\end{array}$ & $\cdots$ & $\cdots$ & $12 \cdot 126$ & $\begin{array}{c}-1 \cdot 036 \\
(-8 \cdot 54 \%)\end{array}$ & $11 \cdot 315$ & $\begin{array}{l}-0.225 \\
(-1.99 \%)\end{array}$ & $21 \cdot 7 \%$ \\
\hline $\begin{array}{r}1952-56 \\
1966-70\end{array}$ & $\cdots$ & $\cdots$ & $\begin{array}{r}11 \cdot 090 \\
9 \cdot 919\end{array}$ & $\begin{array}{c}-1 \cdot 171 \\
(-10 \cdot 56 \%)\end{array}$ & $\begin{array}{l}11 \cdot 090 \\
10 \cdot 293\end{array}$ & $\begin{array}{c}-0.797 \\
(-7.19 \%)\end{array}$ & $68 \cdot 1 \%$ \\
\hline
\end{tabular}


TABLE II

CHANGES IN OBSERYED AGE-SPECIFIC TWINNING RATES BETWEEN 1954 AND 1970 COMPARED WITH CHANGES EXPECTED BY APPLYING WATERHOUSE'S RATES TO PARITY DISTRIBUTION OF ALL MOTHERS IN EACH AGE GROU

\begin{tabular}{|c|c|c|c|c|c|c|c|}
\hline \multirow{2}{*}{\multicolumn{2}{|c|}{ Age Group }} & \multicolumn{2}{|c|}{ Observed Twinning Rate } & \multirow[b]{2}{*}{$\%$ Change Observed } & \multicolumn{2}{|c|}{$\begin{array}{l}\text { Expected Rate from Parity } \\
\text { Distribution of All Mothers }\end{array}$} & \multirow[b]{2}{*}{$\%$ Change Expected } \\
\hline & & 1954 & 1970 & & 1954 & 1970 & \\
\hline $\begin{array}{c}<20 \\
20-24 \\
25-29 \\
30-34 \\
35-39 \\
40-44 \\
45+\end{array}$ & $\begin{array}{l}\because \\
\because \\
\because \\
\because\end{array}$ & $\begin{array}{r}6 \cdot 27 \\
8 \cdot 61 \\
10 \cdot 72 \\
13 \cdot 56 \\
15 \cdot 87 \\
13 \cdot 51 \\
9 \cdot 51\end{array}$ & $\begin{array}{r}6 \cdot 61 \\
9 \cdot 00 \\
10 \cdot 63 \\
12 \cdot 85 \\
13 \cdot 13 \\
8 \cdot 75 \\
5 \cdot 33\end{array}$ & $\begin{array}{r}+5.42 \\
+4.53 \\
-0.84 \\
-5.24 \\
-17.27 \\
-35.23 \\
-43.95\end{array}$ & $\begin{array}{r}6 \cdot 58 \\
9 \cdot 19 \\
12 \cdot 47 \\
15 \cdot 82 \\
18 \cdot 07 \\
13 \cdot 54 \\
7 \cdot 19\end{array}$ & $\begin{array}{r}6 \cdot 52 \\
8 \cdot 94 \\
12 \cdot 07 \\
15 \cdot 47 \\
17 \cdot 83 \\
13 \cdot 38 \\
7 \cdot 01\end{array}$ & $\begin{array}{l}-0.91 \\
-2 \cdot 72 \\
-3 \cdot 21 \\
-2 \cdot 21 \\
-1 \cdot 33 \\
-1.18 \\
-2 \cdot 50\end{array}$ \\
\hline
\end{tabular}

direct estimates are possible. Waterhouse (1950) has published twinning rates for each age-parity maternal group for legitimate births in England and Wales, 1938-48. These rates were applied to the maternal parity distributions of live births in Canada for each maternal age group in 1954 and 1970 (Table II); the difference between the calculated rates for each year indicates the change expected from parity changes alone, on the assumption that the relation of twinning to parity and age is the same in the two years. It is evident that parity changes would not have produced changes greater than $4 \%$ in the twinning rate, so the large falls in the older age groups are not due to parity changes.

Before 1952, neither age nor parity of mothers of twins is known. Table III shows that there was a fall of $1 \cdot 41 / 1,000$ in the crude twinning rate between 1927 and 1942; age alone, by the method used in the previous section, would have produced a fall of $0 \cdot 40 / 1,000$ (28\% of that observed). Application of Waterhouse's data to the age-parity distribution of all mothers in the two years yields an estimate of the fall expected from both age and parity changes: this is $0 \cdot 86 / 1,000,61 \%$ of that observed. Thus parity changes appear more significant in this earlier period than after 1952.

\section{TABLE III}

DIFFERENCES FROM 1927 TO 1942 IN CRUDE AND INDEX TWINNING RATES, AND DIFFERENCE EXPECTED BY APPLICATION OF WATERHOUSE'S RATES

\begin{tabular}{|c|c|c|c|}
\hline Year & $\begin{array}{c}\text { Crude } \\
\text { Twinning } \\
\text { Rate/1,000 }\end{array}$ & $\begin{array}{c}\text { Index } \\
\text { Twinning } \\
\text { Rate }\end{array}$ & $\begin{array}{c}\text { Expected Rate from } \\
\text { Age and Parity } \\
\text { Distribution of All } \\
\text { Mothers }\end{array}$ \\
\hline $\begin{array}{l}1927 \\
1942 \\
\text { Difference } . . \\
\% \text { Difference }\end{array}$ & $\begin{array}{r}12.33 \\
10.92 \\
-1.41 \\
-11.44 \%\end{array}$ & $\begin{array}{l}11.49 \\
11.09 \\
-0.40 \\
-3.48 \%\end{array}$ & $\begin{array}{l}13 \cdot 34 \\
12 \cdot 48 \\
-0 \cdot 86 \\
-6 \cdot 48 \%\end{array}$ \\
\hline
\end{tabular}

\section{TYPE OF TWINNING}

The sex type of each twin pair was recorded up to 1951, and monozygotic and dizygotic twinning rates were estimated by the method of Weinberg (1901) (Fig. 3). Most of the changes are due to changes in the dizygotic rate, although a slight fall in monozygotic twinning is seen after 1927 and during the years 1941-45.

Dizygotic twinning increases sharply with maternal age, whereas monozygotic twinning changes little. thus a fall in dizygotic twinning would be expectee to affect mainly older mothers. It seems likely that. the dizygotic fall seen in the 1926-51 period, and the fall in twinning in mothers over 30 seen after 1952, reflect the same process, i.e., a reduction in dizygotic twinning in older mothers.

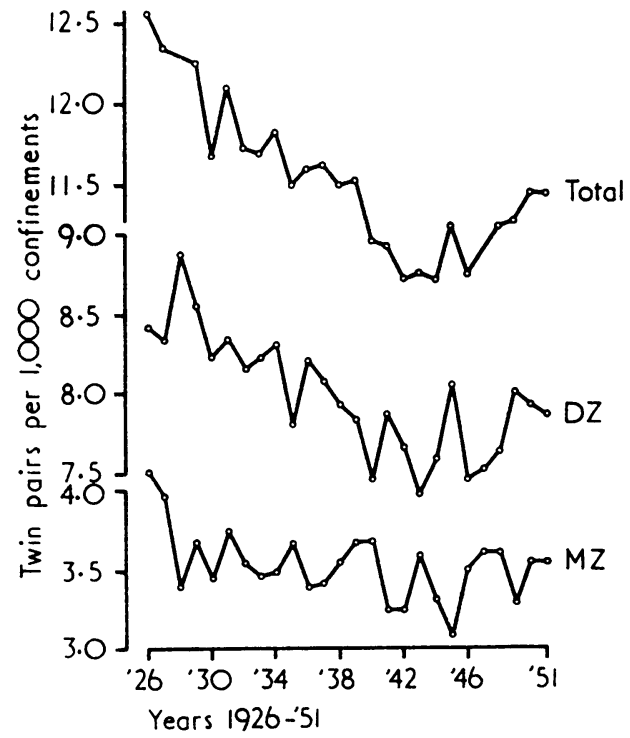

Fig. 3. Dizygotic and monozygotic twinning rates, 1926-51. 
The small 1945 peak seen here is only in dizygotic twinning, and so is not analogous to the 1946 USA peak. There was also a rise in birth rate and in male : female sex ratio in the USA in 1946; neither was present in 1945 in Canada.

\section{Discussion}

The present results are similar to those of Jeanneret and MacMahon (1962) for the white population of the USA. They also showed a fall before 1942, and the beginning of a fall after 1955, which has continued to at least 1964 (Allen and Schachter, 1970). Between 1942 and 1955 the USA rate was more or less stable, with a marked peak in both monozygotic and dizygotic twins in 1946. Apart from this, all changes were, as in this work, in mothers over 30 and in dizygotic twinning. However, they estimate that age and parity changes accounted for no more than $10 \%$ of the fall, whereas the Canadian data, by a similar method of standardization, show that about $22 \%$ of the $1926-52$ decline and $68 \%$ of the later fall were due to age changes, and that parity changes probably accounted for a further fraction of the fall before 1952.

James (1972) has shown falls of $15-25 \%$ between 1950 and 1970 in dizygotic rates for Australia, New Zealand, Belgium, Denmark, England and Wales, Holland, Italy, Norway, Scotland, Sweden, and Switzerland. In each country the fall started abruptly between 1956 and 1964. James suggests that food contaminants, e.g., oestrogens, may be responsible. These changes represent a fall of $10-18 \%$ in total twinning rate; the Canadian fall over the same period was $10 \%$, of which $68 \%$ was due to population age changes. James has not assessed the contribution of population changes to his figures, and it seems likely that most of the fall in these countries could also be due to such changes.
Little is known about the causes of changes in twinning rates after age and parity considerations are accounted for, but 'differential conception', socioeconomic, nutritional, and genetic factors have been considered.

1. The idea of 'differential conception' is based on the finding that mothers of twins are more fecundable than others (Allen and Schachter, 1971). This is shown by their having more pregnancies than other women (Wyshak and White, 1969) and by the excess of twin births in women who became pregnant rapidly, e.g., in conceptions in the first few months of marriage (Bulmer, 1959a), in the early phase of the rapid rise in birth rate in California in 1946 (Allen and Schachter, 1971), and in illegitimate births in Finland (Eriksson and Fellman, 1967).

Thus, in a society without general use of birth control, this group of twin-prone, highly fecundable women will contribute excessively to the total number of pregnancies. As birth control becomes widespread, these mothers do not tend to become pregnant any more often than others and thus their contribution to total births, and therefore the twinning rate, drops. This effect will be more pronounced in older age groups for it is there that the contribution of this highly fecundable group is most marked.

The fall in Canadian twinning rates could be explained by this idea of 'differential conception' related to increasing use of birth control methods. In particular, the rapid fall since 1958 is well correlated with a fall in the birth rate (Fig. 4), presumably due to increasing use of all methods of birth control. The 1945-52 rise might be in part related to the period of rapid family building, accompanied by a rise in birth rate, following wartime restraints, a situation in which overrepresentation of highly fecundable women could be

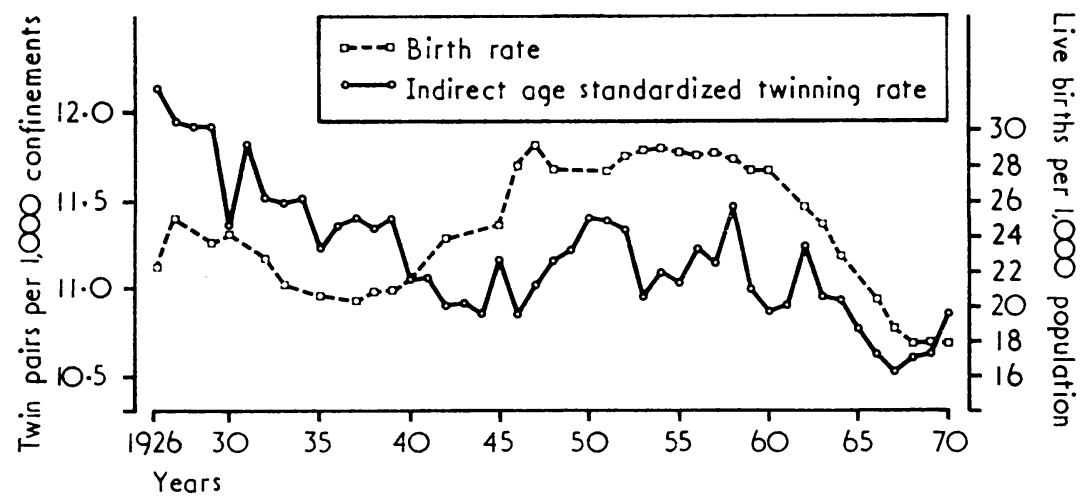

Fig. 4. Live birth rate and twinning rate, 1926-70. 
expected. However, it is difficult to apply the idea to the pre-1945 period when changes in twinning rate were not closely related to changes in birth rate.

2. Bulmer (1959b) suggested that the fall in dizygotic twinning in France, Holland, and Norway during the second world war was due to malnutrition, and similarly the 1945-55 rise in England and Wales has been ascribed to improvements in nutrition (Hytten and Leitch, 1971). Nutritional changes can hardly explain the fall in twinning rates in Canada, as there has been no suggestion of a recent fall in nutritional standards, especially one that could account for the restriction of the fall to mothers under 30 .

3. The economic status of Canadians has steadily improved in the time under study, but previous work suggests that this would, if anything, increase the twinning rate. Thus Myrianthopoulos (1970) found more frequent twinning in the highest socioeconomic groups in the USA. MacGillivray (1970) in Aberdeen showed a higher, though falling, dizygotic rate in taller women whom he states were from higher social classes, although Smith (1966) found no differences with social class in Scotland as a whole. However, Eriksson (1964) has shown lower twinning rates in urban areas in Sweden, and suggests that an urban, sedentary life decreases the chance of carrying a twin pregnancy successfully and thus lowers the twinning rate. In Canada in $196159 \%$ of the population were in urban areas (defined as over 1,000 population) compared with $45 \%$ in 1921 (Census of Canada, 1961), and this increasing urbanization may contribute to the falling twinning rate.

4. Immigration of groups with low twinning rates, e.g., Orientals, would be expected to lower the Canadian rate, but there have been only small changes in the composition of the population (Table IV).

Thus nutritional, genetic, and economic factors do not explain the observed changes, although increasing urbanization may be a relevant factor.

TABLE IV

CANADIAN POPULATION BY ETHNIC ORIGIN (percentages)

\begin{tabular}{|c|c|c|c|c|}
\hline Ethnic Origin & & 1931 & 1951 & 1961 \\
\hline $\begin{array}{l}\text { Great Britain } \\
\text { Rest of Europe } \\
\text { Asia } \\
\text { Indian and Eskimo } \\
\text { Negro } \\
\text { Other and not stated }\end{array}$ & $\begin{array}{l}\cdots \\
\cdots \\
\cdots \\
\cdots\end{array}$ & $\begin{array}{r}51 \cdot 86 \\
45 \cdot 81 \\
0 \cdot 81 \\
1 \cdot 24 \\
0 \cdot 19 \\
0 \cdot 09\end{array}$ & $\begin{array}{r}47 \cdot 89 \\
49 \cdot 06 \\
0 \cdot 51 \\
1 \cdot 18 \\
0 \cdot 13 \\
1 \cdot 22\end{array}$ & $\begin{array}{r}43 \cdot 84 \\
52 \cdot 95 \\
0 \cdot 67 \\
1 \cdot 21 \\
0 \cdot 18 \\
1 \cdot 15\end{array}$ \\
\hline
\end{tabular}

SOURCE: Census of Canada.
Increasing use of birth control methods, by reducing the pregnancy rate of a highly fecundible, twin-prone, subgroup of women towards the average for all women, can explain most of the changes at least since 1958.

\section{SUMMARY}

From 1926 to 1970 the Canadian twinning rate fel by $20 \%$. Analysis of data by type of twin (available only before 1952) shows most of the changes to be in dizygotic twinning, and by age of the mother (available only after 1952) to be restricted to mothers over 30. Indirect standardization shows that changes in the age distribution of the maternal population can account for $22 \%$ of the fall between 1926 and 1951 and $68 \%$ of the fall from 1952 to 1970 . Changes in parity distribution may also contribute in the earlier period. It is suggested that increasing use of birth control methods and perhaps increasing urbanization may have caused these changes.

I would like to thank Mr. C. Moubarak (Statistics Canada) for supplying the data, Dr. S. Walter of this department for statistical criticism, and Professor J. M. Last for help and encouragement.

The author is supported by a Physicians Services Incorporated Fellowship.

\section{REFERENCES}

Allen, G. and Schachter, J. (1970). Do conception delays explain some changes in twinning rates? Acta Genet. med. (Roma), 19, 30.

- , and - (1971). Ease of conception in mothers of twins. Soc. Biol., 18, 18.

Bulmer, M. G. (1959a). The effect of parental age, parity and duration of marriage on the twinning rate. Ann. hum. Genet., 23, 454.

(1959b). Twinning rate in Europe during the war. Brit. med. J., 1, 29.

Census of Canada (1961). Bulletin 7, 1-2. Rural and Urban Population. Dominion Bureau of Statistics, Ottawa.

ERIKsson, A. W. (1964). Pituitary gonadotrophin and dizygotic twinning. Lancet, 2, 1298.

- , and FellmaN, J. (1967). Twinning and legitimacy. స్ స్ Hereditas (Lund.), 57, 395.

Hytten, F. E. and Leirch, I. (1971). In The Physiology ก of Human Pregnancy, pp. 476-487. Blackwell, London.

JAMES, W. H. (1972). Secular changes in dizygotic twinning rates. J. biosoc. Sci., 4, 427.

JeANNERET, O. and MACMAHON, B. (1962). Secular $\stackrel{\mathscr{D}}{+}$ changes in rates of multiple births in the United States. Amer. J. hum. Genet., 14, 410. 
Lilienfeld, A M. and Pasamanick, B. (1955). A study of the variations in the frequency of twin births by race and socio-economic status. Amer. J. hum. Genet., 7, 204.

MacGillivray, I. (1970). Changing incidence of twinning in Scotland in 1939-68. Acta. Genet. med. (Roma), 19, 26.

Myrianthopoulos, N. C. (1970). An epidemiologic study of twins in a large, prospectively studied population. Amer. J. hum. Genet., 22, 611.

SMIтH, A. (1966). Observations on the determinants of human multiple birth. In: Annual Report of the Registrar General for Scotland, 1964, p. 70. HMSO, Edinburgh.
Vital Statistics Annual Reports (1926-70). Published by Statistics Canada, formerly the Dominion Bureau of Statistics, Ottawa.

Waterhouse, J. A. H. (1950). Twinning in twin pedigrees. Brit. J. soc. Med., 4, 197.

WeInBerg, W. (1901). Beitrage zur Physiologie und Pathologie der Mehrlingsgeburten beim Menschen. Arch. ges. Physiol., 88, 346.

WyShaK, G. and WhITE, C. (1969). Fertility of twins and parents of twins. Hum. Biol., 41, 66. 